\title{
Revisitando o vodu: interações e movimentos entre humanos e espíritos em dois contextos haitianos
}

Rodrigo CHARAFEDdine BULAMAH

FLÁVIA FREIRE DALMASO

\section{Alfred Métraux no Haiti}

Duas cenas marcaram a chegada de Alfred Métraux ao Haiti, em princípios dos anos 1940. A primeira delas, nos conta o autor, ocorreu logo após seu desembarque na capital do país. Em Croix-des-Bouquets, perto de Porto-Príncipe, Métraux (1995 [1958]) se deparou com "a enorme pirâmide de tambores e de 'objetos supersticiosos', que se erguiam no pátio do presbitério, esperando o dia estabelecido para um solene auto-de-fé" (Métraux 1995:13). Aquela visão resumia as iniciativas conduzidas pelo Estado e pela Igreja Católica contra práticas e manifestações populares, denominadas "práticas supersticiosas" ou sortilèges. Uma obra do clérigo haitiano que, como não deixa de notar Métraux, não desapontaria seus antecessores dominicanos e agostinianos que faziam a caça ao demônio em colônias espanholas nas Américas (Métraux 1995:12-13). A segunda cena descrita pelo antropólogo suíço retrata uma Porto-Príncipe que, graças aos esforços do governo, "se transforma em um grande centro turístico". "Cada americano que desembarca nesta cidade", continua Métraux, "possui apenas uma palavra à boca: 'vodu', e apenas um desejo, o de ver estas cerimônias que eles imaginam serem cruéis e orgiásticas" (Métraux 1995:47). Assim, sacerdotes (oungan) e sacerdotisas (manbo) se tornaram especialistas em produzir performances destinadas ao consumo de estrangeiros e os santuários e templos “se tornaram salas de espetáculo iluminadas com néon"(Métraux 1995:47).

Esses dois momentos resumem as visões concorrentes sobre magia e religião que coexistiam no período em que Métraux viveu no Haiti. De um lado, as ditas “campanhas anti-superstição” conde- 
navam manifestações populares e pregavam a destruição de templos e artefatos e a perseguição a sacerdotes e a quem mais se dedicasse a "servir aos espíritos", estimulando a conversão ao catolicismo de camponeses e citadinos - processo que acabou por receber o nome popular de larenons (lit., "renúncia") ${ }^{1}$. De outro, apresentações de rituais e danças em hotéis e clubes noturnos para turistas estrangeiros operavam uma folclorização do vodu que, aos olhos de Métraux, funcionava como um agente definitivo de desarticulação cultural ${ }^{2}$. Um esforço legitimamente científico em descrever o vodu era algo que Métraux julgava ausente na literatura especializada à exceção de alguns autores haitianos como, por exemplo, Milo Rigaud (1953) e Jean Price-Mars (2009 [1929]). Todo esse cenário o motivava a tal empreitada: "[O] vodu ainda espera o seu Homero ou, mais modestamente, um bom folclorista que faça o trabalho de fixar a rica tradição oral sobre as divindades de seu panteão" (Metraux, 1995: 16)3․ De fato, se é possível afirmar que o livro Le vaudou hä̈tien, publicado por Métraux em 1958, é a primeira tentativa de sistematização desses conhecimentos e das formas de interação com os espíritos, suas pretensões são bem mais modestas. Métraux se considerava um "homem do trabalho de campo" e suas análises, tanto no Haiti quanto em outras partes do globo, sempre se fizeram numa relação estreita com seu material empírico ${ }^{4}$.

Como uma resposta (intencional ou não) ao trabalho de Métraux, algumas das principais obras e artigos escritos sobre o assunto nos anos que se seguiram à publicação de Le vaudou haïtien mencionaram justamente as dificuldades de sistematizar algo que parece infinito: práticas extremamente heterogêneas que admitem não só diferenças regionais, como também variações relacionadas aos saberes ou estilos pessoais de cada sacerdote (Deren 1953; Metraux 1995; Mintz e Trouillot 1995). Ainda assim, com exceção de alguns poucos exemplos - como o de Karen Richman (2005) - o que vemos são trabalhos que enfatizam uma imagem estável do vodu. Retratados, na maior parte das vezes, de maneira genérica ou através dos olhos de seus sacerdotes e templos, somos levados a conhecer o vodu a partir de sua organização institucional e seus espíritos agrupados em nações, cada qual associada a ritos, danças e alimentação específicos. Apresentado como um conjunto de práticas e conhecimentos associado às obrigações para com os espíritos, à cura e à magia, diversas análises sobre o vodu acabam reduzindo uma pluralidade de formas, conceitos, práticas e afetos a um receituário fixo e a um grupo fechado de deidades, por vezes resumido na ideia de um panteão (ver Deren 1953; Mintz e Trouillot 1995; Brown 1991; Bellegarde-Smith e Michel 2006, entre outros).

\footnotetext{
1 Frente à brutalidade dessas medidas, que pareciam anunciar o desaparecimento do vodu, Métraux iniciou, junto com o escritor e etnólogo haitiano Jacques Roumain, um esforço de salvaguarda que culminou na criação do Bureau d'Ethnologie do Haiti, em 1941. Sua missão inicial era a proteção e a defesa dos objetos, de lugares e de adeptos de uma prática que corria o risco de se extinguir. Para mais informações sobre a fundação do Bureau e seus objetivos na época cf. Charlier-Doucet (2005).

2 Esse processo de folclorização, contudo acabou garantindo uma reinvenção de categorias e de práticas e um modo de reprodução dos rituais mesmo frente a perseguições de diversas ordens, como mostra Kate Ramsey (2011) a partir de uma análise das perseguições e das ressignificações do vodu ao longo do tempo.

3 A referência a Homero aqui não é algo inocente. Para Métraux, o vodu guardava similaridades notáveis com o paganismo da antiguidade clássica, sendo algo reafirmado na conclusão de seu livro e em vários de seus artigos, retratando o vodu como uma religião universal. Esse mesmo movimento é observado também na obra clássica do etnólogo e ensaísta haitiano Jean Price-Mars (2009 [1929]).

4 Ao longo das décadas de 1940 e 1960, a região de Marbial e seus habitantes foram objeto de estudos etnográficos apoiados por um projeto piloto voltado para as áreas de saúde e educação promovido pela UNESCO e coordenado por Métraux. Nos anos que seguiram, esses estudos deram origem a clássicos da literatura antropológica sobre o Haiti, como Making a living in the Marbial Valley (1951) e Le vaudou haïtien (1958), de Alfred Métraux; e La familia rural haitiana, Valle de Marbial (1951), de Rèmy Bastien. Sobre Métraux, ver Laurière (2005); Bulamah (2017) e Dalmaso (2019).
} 
Tais esforços analíticos tiveram, de fato, um impacto na luta política pelo reconhecimento do vodu como uma religião questionando visões que o distinguiam como uma coleção de práticas bárbaras, atrasadas, selvagens e sem qualquer lógica subjacente (Hurbon 1988). Este artigo procura, contudo, apreciar o vodu a partir de formulações nativas recorrentes durante nossas pesquisas etnográficas. Sob esse aspecto o termo revela-se como um conjunto de atividades genericamente chamadas de "serviços" que envolvem danças, preces, alimentação, ritmos e uma série de outras disposições que tem por objetivo promover interações entre pessoas e espíritos. Desse modo, vodou poderia ser considerado, ao mesmo tempo, religião, folclore, conhecimento e magia; um "sistema" que traduz experiências diversas "a partir das quais as pessoas encontram e lidam diariamente com agências invisíveis capazes de afetar as suas vidas e a de seus familiares" (Dalmaso 2018:98).

Entender o vodu como um movimento tanto cotidiano quanto ritual, que, ao invés de justapor, atravessa categorias promovendo conexões e transformações de ordens diversas, nos garante a chance de observar, em outra chave, as dinâmicas, as interações e as variações postas em ação durante rituais, principalmente a partir de danças, da vibração dos tambores e do aquecimento de corpos, objetos e alimentos. Ao mesmo tempo, essa alternativa permite explorar trajetórias de vida e percursos que podem e, de fato costumam ser alterados como consequência direta da interação diária entre pessoas, entidades espirituais e novas demandas situacionais. Tal fato nos abre a possibilidade de crítica à própria noção de religião, por vezes entendido como um fenômeno inerte no tempo e no espaço e não como um processo histórico sujeito a mudanças constantes.

Se, na época em que Métraux realizou seu trabalho de campo, o avanço contra o vodu era promovido sobretudo pela Igreja Católica, atualmente são as igrejas protestantes os principais agentes de um esforço que busca desarticular e combater as interações entre casas, pessoas e espíritos. Isso ocorre, como veremos, a partir de uma leitura que, longe de desacreditar na agência dos espíritos, os demoniza, reclassificando-os como "diabos", "satãs" e "coisas velhas" (djab, satan, vye bagay). Com efeito, cabe destacar que as igrejas protestantes no país não são homogêneas, se assemelhando mais a formas institucionais e religiosas híbridas, como o catolicismo popular que floresceu no país de modo virtualmente irrestrito até 1860, quando o Vaticano finalmente reconheceu o Haiti como país independente para alguns anos depois, iniciar as campanhas antisuperstição5. Com isso em mente, é possível pensar o modo como diferentes "protestantismos" (Bastian 1992; Mézié 2016) se conformam no espaço social haitiano, dentro e fora das fronteiras, encontrando suportes institucionais e formas de interações com práticas, histórias, agências e categorias as mais diversas ${ }^{6}$.

5 Haiti e República Dominicana dividem o território da antiga ilha de Hispaniola, colonizada inicialmente pela Espanha. Em 1697, o Tratado de Ryswick dividiu a ilha e deixou à França o terço ocidental do território, à época ainda pouco explorado e ocupado apenas marginalmente por colonos de origem francesa. A colônia de São Domingos, como ficou conhecida, foi uma das mais prósperas do Caribe e sua economia assentava-se no trabalho de africanos escravizados e na plantation açucareira. O período que vai de 1791 a 1804 , e que hoje definimos como Revolução Haitiana, viu surgir uma série de revoltas e negociações encabeçadas por africanos/as e seus descendentes escravizados/as além de "pessoas de cor" livres que culminou na independência do país. O reconhecimento desta libertação, contudo, não foi imediata. A antiga metrópole só o fez 25 anos depois e mediante o pagamento de uma indenização de 150 milhões de francos, o equivalente à cerca de 21 bilhões de dólares em valores atuais. O Vaticano, por sua vez, também não reconheceu o Haiti até 1860 . Só a partir de então, um clérigo francês ganhou predominância no país e passou a gerir as igrejas, associando-se ao Estado no controle do sistema de ensino nacional.

6 Para uma releitura do trabalho de Bastian que propõe uma descrição dos diferentes processos históricos e sociais que conformaram e conformam os protestantismos no Haiti, ver Richman (2008). Para um importante balanço histórico sobre os pentecostalismos no Haiti, ver Mézié (2016). 


\section{Heranças e espíritos}

Escrito a quatro mãos e priorizando uma perspectiva etnográfica, o presente texto está baseado em duas experiências distintas de pesquisa de campo, uma localizada no norte e outra no sul do Haiti ${ }^{7}$. Nosso objetivo é colocar em diálogo certos eventos nos quais o caráter versátil e avesso a sistematizações inerente ao vodu se mostrou extremamente relevante. Em diversas partes do país e em contextos transnacionais, observamos como, diariamente, espíritos e outras entidades místicas são protagonistas na definição de formas relacionais, afetos e diferentes maneiras de se estar no mundo. Nesse sentido, vale sublinhar que interações entre espíritos e pessoas acontecem tanto em ações cotidianas quanto em momentos rituais sendo parte de compromissos cósmicos herdados em linhas bilaterais de descendência por meio de um coletivo denominado eritaj (herança) ou, ainda, estabelecidos por meio de "contratos", principalmente a partir da compra e venda de entidades conhecidas como pwen ${ }^{8}$.

Em diversos locais do país, uma herança abarca um conjunto de relações e elementos que circulam e se refazem ao longo de linhas de descendência e que definem uma coletividade como fanmi (família) (Lowenthal 1987; Richman 2005; Bulamah 2013; Dalmaso 2018; 2019) ou, como se costuma dizer, "pessoas que pertencem umas às outras" (moun mwen, lit. gente minha, com variação do pronome conforme o caso) (Dalmaso 2014). O "sangue" (entendido aqui como um artefato cultural), a terra familiar (chamada de lakou ou abitasyon), os mortos (lemó) e os espíritos - conhecidos no norte como zanj ou jany e no sul como lespri ou lwa - são, guardadas certas diferenças regionais, os pilares dessa herança e localizam uma pessoa em um conjunto de relações que envolvem compromissos entre ancestrais e contemporâneos (Bulamah 2019). Ademais, espíritos vivem em um local místico denominado África-Guiné (Lafrik Gine) ou ainda "embaixo d'água” (anba dlo) e transitam entre espaços de morada da terra familiar como árvores, casas, grutas e rochedos. Fundamentalmente, esses espíritos são concebidos como potências que circulam pelo sangue da família ou, como se costumar ouvir em diferentes partes do Haiti, "os espíritos caminham em nosso sangue" (lwa mache nan san nou).

Portanto, ao olharmos para a materialidade das trocas e das relações entre pessoas e espíritos, buscamos menos a postura de um Homero ou a de um folclorista e mais a de pesquisadores(as) comprometidos(as) com a complexidade da vida cotidiana fugindo de reduções que tentam ler fenômenos sociais a partir de genealogias e generalizações inspiradas em fenômenos euro-americanos. Lembramos ainda que esse texto deve ser lido como um primeiro exercício empreendido por nós na elaboração de uma análise dessas lógicas e interações com os espíritos em uma perspectiva processual que inclua também o papel de outras agências, de materialidades diversas e de outros contextos situacionais, como as conversões religiosas e o avanço de igrejas protestantes pelo país.

\footnotetext{
7 Flávia Dalmaso realizou pesquisa de campo no sul do país, entre os anos de 2008 e 2016, quando era aluna do PPGAS no Museu Nacional da Universidade Federal do Rio de Janeiro. Entre 2010 e 2017, Rodrigo Bulamah fez seu trabalho de campo no norte, como aluno de Antropologia Social da Universidade Estadual de Campinas e, posteriormente, também vinculado à École des Hautes Études em Sciences Sociales (França). Nos dois casos, as pesquisas compuseram nossas investigaçóes tanto de mestrado quanto de doutorado e centraram em temas como parentesco, mobilidade, religião, tempo e história.

8 Não é nosso objetivo aqui descrever as relaçóes estabelecidas quando as pessoas decidem comprar ou vender um pwen. Para mais detalhes sobre o assunto cf. Fiod (2019); Brown (1991:151-152); Richman (2005:166-177 et passim).
} 
Em um plano mais geral, procuramos dialogar com algumas produções antropológicas recentes tais como Traveling spirits: migrants, markets and mobilities (Hüwelmeier e Krause 2010) e The social life of spirits (Blanes; Espírito-Santo 2014), coletâneas cujos autores buscam contemplar exatamente esse convívio concreto e imediato entre pessoas e entidades não-humanas em diferentes situações (ver também Mello 2016). Além disso, acreditamos que a aproximação de nossas experiências de pesquisa servirá, por um lado, para testarmos as possibilidades e os limites de um esforço comparativo que leve em conta dois contextos regionais haitianos e, por outro, para repensarmos a validade de uma proposta que possa analisar o vodu não só dentro das fronteiras nacionais, mas também suas interações com fluxos, câmbios e trânsitos globais.

\section{Em direção ao Norte}

Lolit era a quarta filha do casal André e vivia com os pais em um povoado rural da região de Milot, ao norte do Haiti. Enquanto suas irmãs, acompanhadas por outras crianças do povoado, percorriam logo cedo o caminho sinuoso até a escola, no centro da comuna, Lolit costumava se atrasar e, por vezes, fazia o trajeto na garupa de um moto-táxi. Como era comum nas casas do povoado, Lolit ajudava sua mãe no preparo da comida ou em algum outro serviço doméstico como lavar roupa ou buscar água no poço ou em algum riacho próximo ao povoado. Porém, o fazia sempre que lhe conviesse. "Lolit é louca" era uma frase que se ouvia habitualmente por ali, tanto de gente de sua casa quanto da vizinhança.

$\mathrm{Na}$ casa de quatro cômodos, ela dormia junto de suas irmãs e da pequena afilhada de sua mãe, com quem dividia as atividades diárias, enquanto seus dois irmãos mais velhos, que moravam na casa ao lado, levavam os poucos animais que a família tinha aos pastos ou iam trabalhar nas roças de onde todos tiravam seu sustento. Lolit estava aprendendo a ser mercadora, como sua mãe costumava dizer. Por vezes as duas iam juntas ao mercado de Cabo Haitiano, capital da região Norte, onde vendiam o que a família havia produzido no roçado, como batata doce e feijão ou frutas, dentre as quais toranja, pinha e fruta-pão. Contudo, Lolit estava recebendo também outros ensinamentos. "Conhecimentos", como ela costumava dizer, que deixavam sua mãe mais preocupada do que orgulhosa. Dos seis filhos do casal André, Lolit havia sido "reclamada", isto é, reivindicada por espíritos para se tornar uma sacerdotisa e conduzir os compromissos familiares. Era uma herança a que ela devia tanto respeito quanto "serviços" e que, se ignorada, traria consequências fatais à ela e à família.

Na casa de madame André, tanto a sua família quanto a de seu marido eram pessoas que tradicionalmente serviam aos espíritos. Certa vez, ao falar de seus antepassados e dos de seu marido, madame André afirmou que "eles eram grandes servidores". Isso implicava que um conjunto de espíritos eram parte constitutiva da família e que, por isso, tinham que ser servidos e agradados. Ela se lembrava bem das cerimônias que seu pai organizava em homenagem a estas entidades e falava sempre de seu tio-avô que era um conhecido sacerdote da região. Além disso, sua irmã mais nova tinha logo cedo despertado uma proximidade com os espíritos e, com o tempo, havia se tornado uma sacerdotisa. Contudo, nem

9 Parte do material que discutimos aqui foi analisado em um artigo anterior cujas conclusões são reformuladas neste texto. Ver Bulamah (2015). 
todos de sua família tinham esse apreço pelas relações com estes seres. Ainda jovem, madame André foi levada pela madrinha à Igreja Apostólica de Milot, uma das tantas igrejas protestantes da região, e criou seus filhos ali, num esforço por distanciar-se dos compromissos herdados com os espíritos.

O relato dessa conversão de madame André encontra paralelo com algo que Métraux (1995 [1958]) já observara em sua etnografia no sul do país. Ao tratar da relação entre vodu e protestantismo, o autor mostra que muitos haitianos e haitianas se convertiam em busca de um refúgio que os afastasse dos compromissos familiares e espirituais: "O protestantismo aparece, então, como um asilo ou, para ser mais preciso, como um círculo mágico onde se está ao abrigo dos loas e dos demônios" (Métraux 1995:312, grifos nossos). Nesse sentido, a conversão nada mais é do que "a expressão de uma crença excessiva nos espíritos" (idem) e tal processo aparece menos como uma crise de consciência ou uma negação do poder destes entes do que a reafirmação de sua força e de seu lugar no mundo.

Assim, apesar do esforço de madame André, sua filha Lolit, ao chegar aos 15 anos, foi reclamada. Apesar das tentativas da família em distanciá-la desse chamado, Lolit não conseguia frequentar os cultos protestantes, pois desmaiava ou se descontrolava. Era um sinal de que ela havia sido escolhida para levar à frente as obrigações familiares com tais entidades. Numa consulta à sua irmã sacerdotisa, madame André teve dimensão da gravidade daquele ocorrido e da necessidade de financiar a iniciação de sua filha. Como ela mesmo ponderou, "se eu não lhe der dinheiro, Lolit pode me matar".

É no célebre ensaio de Marcel Mauss (2003) que encontramos um importante argumento sobre a centralidade e os riscos que podem envolver as trocas com os espíritos. Como nota o antropólogo:

Um dos primeiros grupos de seres com os quais os homens tiveram de estabelecer contrato, e que por definição estavam aí para contratar com eles, eram os espíritos dos mortos e os deuses. Com efeito, são eles os verdadeiros proprietários das coisas e dos bens do mundo. Com eles é que era mais fácil e necessário intercambiar e mais perigoso não intercambiar. Mas, inversamente, com eles era mais fácil e mais seguro intercambiar (Mauss 2003:206, grifos nossos).

Essa "necessidade de intercâmbio" e os perigos do não cumprimento dessas obrigações são particularmente notáveis em Milot. Ao estabelecer um contato direto com os espíritos, por meio de oferendas, homenagens festivas e possessões, Lolit dava continuidade aos compromissos herdados e renovava as trocas com os espíritos. De fato, ao ser "montada” e manifestar corporalmente a presença dos espíritos, Lolit recebia parte de sua herança, operando aquilo que Roger Bastide (2018) observou como uma das funções principais da possessão: a conexão entre parentes vivos e antepassados que atualiza o próprio parentesco ao torná-los contemporâneos.

De fato, ser responsável pelos espíritos implica em fazer as coisas circularem por meio de dádivas variadas, como comidas produzidas no roçado, além de bebidas alcóolicas, moedas, músicas e danças. Em cerimônias, fica evidente a centralidade do movimento enquanto o motor das trocas. São as músicas, as danças e os alimentos oferecidos aos espíritos que os atraem. Todo o cenário é montado previamente com a comida sendo disposta em lençóis, mesas, cestos e cuias, além de perfumes, velas e flores. À medida em que uma cerimônia avança acompanhada do aumento da música e dos movimentos, atinge-se um estado 
conhecido como chofe (quente, aquecido). Esse estado propicia a vinda gradativa dessas entidades e intensifica suas interações com humanos, com os objetos e com as formas sonoras e materiais presentes.

Se o contexto nacional é atualmente bastante distinto daquele observado por Métraux, ainda é notável uma tensão entre religiões institucionalizadas e as práticas tradicionais. Se a Igreja católica se mostra mais tolerante às práticas populares e à própria magia, são as religiões protestantes que se posicionam mais frontalmente contra essas formas de interação ritual e cotidiana com espíritos. Tal fato se dá por meio de uma postura contrária a tais entidades que aparece mais explicitamente numa condenação ao movimento. Nos cultos e celebrações da Igreja Apostólica de Milot, frequentada pela família André, o movimento era evitado por meio de palavras de pastores e condutores de cultos que frequentemente pediam aos presentes: "segurem seus corpos", "não tremam" e "não se deixem levar". A tensão familiar entre Lolit e sua mãe, se realizava, nesse sentido, como uma tensão entre diferentes formas de dar conta das heranças e compromissos geracionais, que apontavam para uma dimensão existencial que atrela a vida ao movimento (Premawardhana 2018). Isso tudo se abria a novas possibilidades relacionais - muitas das quais os espíritos não estavam excluídos. Olhemos para o sul do país para melhor enxergar esses arranjos.

\section{Olhando ao sul}

Enese é professora em um programa de alfabetização para adultos em Lepwa, pequeno povoado rural situado a cerca de 20 minutos de moto do centro de Jacmel, maior cidade e capital do Departamento Sudeste. Embora a região de Lepwa seja majoritariamente católica, Enese e sua família (seu pai, sua mãe e um de seus irmãos) frequentam a igreja Batista. Mas nem sempre foi assim. Quando se casaram, na década de 1950, os pais de Enese eram "servidores", isto é, serviam aos espíritos de suas famílias, uma herança que persistia por gerações. Esses seres, conhecidos no sul como lwa bitasyon (espírito da terra), lwa fanmi (espírito da família) ou lwa eritaj (espírito da herança) são entidades duplamente ligadas à família: primeiro porque circulam no sangue de todos os descendentes de um determinado ancestral, isto é, pela sua eritaj; segundo porque costumam morar na terra (abitasyon) que esse ancestral primeiramente ocupou e onde ainda continuam vivendo pelo menos parte de seus familiares.

É comum encontrarmos na literatura que trata do vodu referências a um determinado panteão de entidades representativas desse universo como, por exemplo, Ezili Dantor, Papa Legba, Ogou, Dambalah, Kouzen Zaka, Bawon Samdi, dentre outros. Também é comum esbarrarmos em classificações que alocam esses espíritos em diferentes nações ou famílias de acordo com os seus respectivos gostos e personalidades, tais como Rada ou Petro. Apesar disso, quase nada é dito a respeito dos lwa bitasyon que cruzam nossas pesquisas quando deslocamos o ponto de observação dos templos para as casas; das festividades - em certo sentido - mais formais para a imponderabilidade que caracteriza a vida cotidiana. No Sul, esses espíritos possuem nomes próprios bem específicos, ainda que na maioria das vezes sejam considerados "qualidades" ou versões daqueles mais conhecidos, de maneira que "[c]ada família, por exemplo, herda suas próprias Erzulies, seus próprios Dambalas e seus próprios Ogouns” (Murray 1980:301). Em outras palavras, assim como Ogou Ferray e Ogou Batagri representam, por exemplo, "tipos" de Ogou, Kè Boulè 
(um nome único) espírito que pertencia (um nome único) a uma das famílias de Lepwa, se apresenta como uma versão de Ogou, ainda que nem sequer utilize esse prenome para se identificar.

Considerando, ainda, o deslocamento proposto nas linhas acima, vemos serviços que consistem em celebrações simples, muitas vezes desprovidos de elementos considerados importantes pela literatura a respeito do vodu, como por exemplo o ason (chocalho que é visto como símbolo do sacerdócio e utilizado para chamar os espíritos) ou até mesmo os próprios atabaques (tanbou). Existem muitas formas de se comunicar com os lwa, diziam os moradores de Lepwa, o que faz com que cada um esteja livre para efetuar isso da maneira como achar melhor, ainda que para tanto seja necessária uma constante negociação com os lwa.

Era mais ou menos esse o cenário em que se desenrolavam os serviços feitos pela família de Enese antes de seu nascimento. No entanto, o fato de seus pais perderem os primeiros quatro filhos, que morriam ainda bebês, os levou a desconfiar de que havia algo errado. Consultaram um sacerdote das redondezas e, por meio dele, conversaram com o espírito da família que os protegia e os amparava. Ele então lhes revelou o problema: estavam sendo alvo de uma perseguição. Em outras palavras, como haviam suspeitado, a morte prematura dos filhos não tinha nada de "natural". Ao contrário, sua causa era uma intervenção mística, mais precisamente uma ekspedisyon (expedição) situação na qual uma pessoa próxima "envia" uma potência maligna (para aquele que a recebe) com o intuito de prejudicar alguém de quem sente ciúmes ou inveja.

Ter seus filhos "comidos" (manje), ou seja, mortos, por uma "perseguição" desse tipo é uma das piores coisas que podem acontecer e uma situação temida por muitos. Tais circunstâncias, como aponta Fiod (2019), abrem espaço para acusações de feitiçaria entre vizinhos e, por vezes, dentro da própria casa. Combater um feitiço com outro, isto é, enviando um espírito mais poderoso para contra-atacar o primeiro é uma das medidas habitualmente tomadas para se reverter circunstâncias como essa. Mas, nesse caso, a posição do lwa da família se traduziu em um recuo. $\mathrm{Na}$ fala do espírito da família "Ele (o espírito maligno) é mais forte do que eu, mudem seu rumo!”. Para os pais de Enese a mensagem foi clara: "mudar de caminho" foi prontamente entendido como um apelo para "entrarem na igreja", abrindo a possibilidade para que outra entidade - Jesus Cristo - assumisse o protagonismo na salvaguarda e na direção de suas vidas ${ }^{10}$.

Situações como essa, onde os próprios espíritos recomendam o ingresso em denominações protestantes, apesar de não serem incomuns, não são frequentes em Jacmel. Ainda assim podemos, uma vez mais, nos aproximar das observações de Métraux. Como afirma o autor, a conversão aparece como um último recurso para se fugir de formas de aflição sejam elas promovidas por figuras malignas próximas (da casa ou da vizinhança) ou motivadas por algum descontentamento dos espíritos: "Quando esgotam-se todos os recursos do vodu - 'serviços', banhos, chás, expulsão dos mortos - experimenta-se, como último recurso, o remédio radical: a conversão a alguma seita protestante”. E mais, como destaca

10 Embora não explorada no presente artigo, a noção de "guerra espiritual", acionada por uma série de denominações protestantes no Haiti, e que localiza de um lado os espíritos familiares, vistos como demônios pertencentes ao exército de satã e, do outro, o próprio Espírito Santo faz todo o sentido aqui. Além disso como inventivamente argumenta Ramsey (2014, p. 192), essa "guerra" adquire um significado particular quando se leva em consideração o pacto inicial feito no Haiti durante a cerimônia de Bois Caïman. Como a autora constata (idem) esse pacto é considerado demoníaco pelas igrejas evangélicas e origem de todos os males que aconteceram e acontecem no país. 
Métraux, “[p]or vezes, é o próprio hougan que, ao constatar o fracasso da cura prescrita, aconselha seu paciente ou sua família a abandonar os lwa e tentar o protestantismo" (idem, grafia no original).

Há uma série de igrejas denominadas protestantes no Haiti que incluem desde religiões mais antigas, como a batista, até as formações pentecostais mais recentes. De maneira geral, o discurso pregado pelos pastores durante os cultos não nega a existência dos lwa. Tomando-os como demônios dos quais é preciso se proteger, a ordem é se afastar de todas as práticas associadas ao vodu. Em outras palavras, a ideia é interromper quaisquer canais de comunicação e interação com os espíritos e, dessa maneira, se tornar imune as suas ações malevolentes (Dalmaso 2019). Assim, o caminho seguido pelos pais de Enese produziu um resultado positivo: após tornarem-se "pessoas da igreja” (moun legliz) conceberam 10 filhos, todos absolutamente saudáveis. Já o espírito sofreu o que chamaram de negligência, sendo esquecido com o passar do tempo.

Experiências com situações semelhantes nos levam a crer, entretanto, que tal desfecho não deve ser encarado como uma situação necessariamente estável ou terminada. Como bem lembrado por Meyer (1998:318), apesar do apelo comum nos círculos pentecostais por uma ruptura completa com o passado tradicional rumo à modernidade, frequentemente nos deparamos com "a inabilidade dos crentes de romper completamente" com esse passado. Nesse sentido, ao mesmo tempo em que Métraux tem razão ao destacar a conversão como uma terapêutica entre tantas outras, ela não necessariamente representa - como Métraux argumentava - um ponto final nas relações com os espíritos, estando sujeita a uma série de compromissos familiares, a escolhas individuais e ao protagonismo desses próprios espíritos. Como exemplificado no primeiro relato, a chance de alguém da família (seja ela adepta do protestantismo ou não) ser "reclamado", isto é, solicitado em algum momento a continuar as relações de troca com o lwa não só é possível, como também muito provável ${ }^{11}$. Talvez por causa disso, Simon, um jovem morador de Lepwa, tenha tantas vezes afirmado que "sempre sobra alguém" - uma pessoa que continua a realizar os serviços para os espíritos da família, conservando o movimento e reestabelecendo a reciprocidade entre as gerações, entre os espíritos, os vivos e os ancestrais.

\section{Conversões, travessias, caminhos, movimentos}

Os dramas que a família André vivia mencionados no primeiro relato não lhes são exclusivos. Outras famílias de Milot, em geral, vivem em proximidade com espíritos, lhes devendo dádivas, como presentes, festas e respeito, e os entendendo como parte de uma herança e de uma história comuns. Tampouco são únicas as perseguições sofridas pelos pais de Enese antes de entrarem para a igreja e de conceberem 10 filhos com saúde. Pelo contrário, como chamamos atenção anteriormente, boa parte desses espíritos pertencem à família, estando ligados ao mesmo tempo a um determinado território, ao seu primeiro proprietário e a todos os seus descendentes o que, muitas vezes, lhes confere o poder de intervir direta ou indiretamente em suas vidas. Tais situações - nas quais espíritos e pessoas, longe de

11 A conversão de um passado representado por um modo de vida e práticas vistas como "tradicionais" para um presente "moderno" traduzido pela adesão ao protestantismo e para as religiões pentecostais ou neopentecostais, apesar de não ser discutida aqui, é um ponto comum levantado por muitos autores que trabalham com o tema da migração e da proletarização de haitianos em contextos transnacionais. Para mais informações sobre o assunto cf. Meyer (1998) e, particularmente para o contexto haitiano, Richman (2008). 
pertencerem a universos materialmente apartados, partilham uma existência marcada por interações cotidianas - nada tem de extraordinário.

Nesse sentido, tomar o vodu enquanto movimento e não como uma religião institucionalizada e circunscrita possibilita iluminar justamente essa participação mútua de espíritos, ancestrais e vivos; entendendo-o antes, como um jogo complexo atravessado por tempos e espaços diversos. Na prática, essas relações são fundantes da própria noção de pessoa no Haiti e garantem que os sujeitos possam refazer seus laços de parentesco com antepassados, mortos e contemporâneos, servindo aos espíritos e colocando dádivas geracionais em circulação. É importante destacar ainda o caráter muitas vezes momentâneo e multidirecional que marcam as conversões entre adeptos do vodu, do catolicismo ou dos protestantismos. Assim, se é fato que muitas vezes, a conversão ou mudança de caminho é necessária para que se inicie determinados processos terapêuticos de cura e tratamento de doenças, o primeiro caso descrito aqui revela que ela pode ocorrer também na direção contrária, com pessoas que cresceram frequentando igrejas protestantes sendo reclamadas a levarem à frente compromissos herdados com os espíritos.

Como procuramos demonstrar, a ideia da conversão pode discursivamente enfatizar o abandono dos compromissos herdados e, consequentemente, um distanciamento com relação aos espíritos e à própria família. Especialmente, a ruptura com o passado implica na interrupção de todos os fluxos que caracterizam o vodu impondo um corte na teia que entrelaça mortos, vivos, espíritos e terras. Sob esse aspecto, como nota Premawardhana (2018) para o caso de povoados rurais situados no norte de Moçambique, o "modelo" de conversão proposto pelas igrejas protestantes, no qual a morte - ao invés de traduzir uma continuidade do movimento de trocas e dádivas geracionais e uma continuidade de relações - se apresenta como o fim ou, no máximo, como um longo tempo de repouso junto a Jesus e à espera do dia do juízo final. A conversão acaba se definindo como "um movimento [de ruptura] para acabar com todos os movimentos" (Premawardhana 2018:37). A isso soma-se, ainda, a promessa de uma nova família: uma família centrada em Deus e na qual os que frequentam a igreja se tornam irmãs e irmãos a partir de um novo batismo (ver Fry 2000).

De fato, esse parece ter sido o caso de Enese e seus familiares, explorado no segundo relato, ainda que tal exemplo não possa, como nossos próprios interlocutores advertem, ser tomado como encerrado ou visto como uma situação permanente. Justo pelo contrário, o que nossas pesquisas revelam é um cotidiano marcado por interações entre agências de natureza diversa que redundam em circunstâncias que muitas vezes fogem ao controle das pessoas. Assim, como demonstrado na primeira descrição etnográfica, essa nova família pode muitas vezes estar alheia aos dramas cotidianos e a forças malignas que exigem a presença e a ação dos espíritos. Isso permite ver a conversão não como um processo unidirecional, mas como algo heterogêneo e instável. Assim, o próprio emprego do termo "conversão" deve ser cuidadoso e consciente, pois ele pode não expressar completamente as experiências religiosas vivenciadas por pessoas nos contextos de avanço das variadas formas do pentecostalismo. Primeiro, porque seu uso no dia a dia é raro, existindo outras maneiras mais frequentes de anunciar e falar sobre a adesão ao protestantismo, dentre as quais "mudar de caminho" ou "entrar ou caminhar na igreja" são apenas algumas. Em segundo, porque ele pode acabar transmitindo a falsa percepção de que essa 
adesão institui uma ruptura clara e definitiva, uma imagem que não reflete as práticas empregadas por aqueles e aquelas com os quais convivemos no Haiti.

Mais uma vez, tais posturas revelam que os protestantismos antes de promoverem uma ruptura com o passado fazem parte de um jogo complexo que envolve história, parentesco, agência, pessoa e o lugar central da mobilidade existencial nestes contextos. Como resume Karen Richman (2008:4), "Catolicismo, vodu e protestantismo, as três religiões haitianas oficialmente reconhecidas, se definem mutuamente, mediam e reproduzem uma à outra na paisagem religiosa fluída, plural e transnacional do Haiti, que se estende para além do país (...) seja onde for que residam haitianos e haitianas (...)”. Menos do que oposições ou formas religiosas contrárias e estanques, a relação entre protestantismos, catolicismo e vodu parece compor uma relação de figura e fundo ou ainda a de um caleidoscópio que hora traz à frente um dos elementos que os compõem enquanto obscurece outros - podendo até mesmo produzir uma imagem invertida ou imagens diferentes em diferentes momentos.

Nisso, as exigências e trocas com os espíritos encontram seu espaço a partir de novos arranjos familiares que tentam dar conta de diferentes agências e de seus efeitos reais - ou como definiu certa vez uma de nossas interlocutoras, “é assim a família, uma parte em Deus, uma parte de servidores".

\title{
Rodrigo Charafeddine Bulamah é
}

\author{
Flávia Freire Dalmaso
}

\section{REFERÊNCIAS BIBLIOGRÁFICAS}

BASTIAN, Jean-Pierre. 1992. "Les protestantismes latino-américains: un objet à interroger et à construire". Social Compass, 39(3): 327-354.

BASTIDE, Roger. 2018. "O princípio de individuação (contribuição a uma filosofia africana)". Cadernos de Campo, 27(1): 220-232.

BASTIEN, Rèmy. 1951. La familia rural haitiana. Cidade do México: Mexico libra publications. BLANES, Ruy; ESPÍRITO-SANTO, Diana. 2014. "Introduction: on the agency of intangibles". In: R. Blanes e D. Espírito-Santo (orgs.), The social life of spirits. Chicago e London: University of Chicago Press.

BROWN, Karen McCarthy. 1991. Mama Lola: A Voodoo Priestess in Brooklyn. Berkeley, CA: University of California Press.

BULAMAH, Rodrigo C. 2019. “Ancestrais”. In: NEIBURG, F. Conversas etnográficas haitianas. Rio de Janeiro: Papéis Selvagens.

.2017. Alfred Métraux: Between Ethnography and Applied Knowledge. In: BEEZLEY, W.

(ed.). Oxford Research Encyclopedias - Latin American History. Nova Iorque: Oxford University Press, 2017, p. 1-31. 
2015. Um lugar para os espíritos: os sentidos do movimento desde um povoado haitiano.

Cadernos Pagu, 45, p. 79-110.

.2013. O cultivo dos comuns: parentesco e práticas sociais em Milot, Haiti. Dissertação de mestrado. Programa de Pós-Graduação em Antropologia Social, Universidade Estadual de Campinas. CHARLIER-DOUCET, Rachelle. 2005. "Anthropologie, politique et engagement social. L'expérience du Bureau d'ethnologie d'Haïti". Gradhiva. Revue d'anthropologie et d'histoire des arts, 1: 109-125.

DALMASO, 2019. “Família”. In: NEIBURG, F. Conversas etnográficas haitianas. Rio de Janeiro: Papéis Selvagens.

. 2018. "Heranças de família: terras, pessoas e espíritos no sul do Haiti." Mana. Estudos de Antropologia Social 24(3), pp. 96-123.

.2014. Kijan moun yo ye? As pessoas, as casas e as dinâmicas da familiaridade em Jacmel/Haiti. Tese de doutorado, Museu Nacional/UFRJ.

DEREN, Maya. 1953. Divine Horsemen: The Living Gods of Haiti. London: Documentext McPherson \& Company.

FIOD, Ana. 2019. “Feitiço”. In: NEIBURG, F. Conversas etnográficas haitianas. Rio de Janeiro: Papéis Selvagens.

FRY, Peter. 2000. “O Espírito Santo contra o feitiço e os espíritos revoltados: 'civilização' e 'tradição' em Moçambique”. Mana, 6(2): 65-95.

HURBON, Laënnec. 1988. Le barbare imaginaire. Porto-Príncipe: Éditions Henri Deschamps. HÜWELMEIER, Gertrud ; KRAUSE, Kristine (orgs.). 2010. Traveling spirits: migrants, markets and mobilities. Londres e Nova Iorque: Routledge.

LAURIÈRE, Christine. 2005. “D’une Île à l'autre: Alfred Métraux En Haïti”. Gradhiva : Revue d'histoire et d'archives de l'anthropologie 1: 181-207.

LOWENTHAL, Ira P. 1987. "Marriage Is 20, Children Are 21: The Cultural Construction of Conjugality and the Family in Rural Haiti”. Tese de doutorado, Baltimore: Johns Hopkins University. MAUSS, Marcel. 2003. "Ensaio sobre a dádiva. Forma e razão da troca nas sociedades arcaicas”. In: Sociologia e antropologia, traduzido por Paulo Neves. São Paulo: Cosac Naify. p. 183-314.

MELLO, Marcelo M. 2016. Entidades espirituais: materializações, histórias e os índices de suas presenças. Etnográfica, 20(1): 209-223.

MÉTRAUX, Alfred. 1995 [1958]. Le Vaudou haïtien. Paris: Gallimard. . 1951. Making a living in a Marbial Valley. Paris: UNESCO.

MEYER, Birgit, 1998. “'Make a complete break with the past': memory and the post-colonial modernity in Ghanaian pentecostalist discourse”. Journal of religion in Africa, 28(3): 316-349.

MÉZIÉ, Nadège. 2016. "Emergência e ascensão dos protestantismos no Haiti: um panorama histórico". Debates do NER, 17(29): 289-327.

MICHEL, Claudine. BELLEGARDE-SMITH, Patrick (orgs.) 2006. Vodou in Haitian Life and Culture: Invisible Powers. New York: Palgrave Macmillam.

MINTZ, Sidney; TROUILLOT, Michel-Rolph. 1995. “The social history of haitian vodou”. In: CO- 
SENTINO, Donald J. (org.). Sacred arts of Haitian vodou. Los Angeles: UCLA Fowler Museum.

MURRAY, G. Population pressure, land tenure, and voodoo: the economics of Haitian peasant ritual. 1980. In: ROSS, E. (ed.) Beyond the myths of culture. Nova Iorque, Academic Press, pp. 295-321. PREMAWARDHANA, Devaka. 2018. Faith in flux: Pentecostalism and mobility in rural Mozambique. Philadelphia: University of Pennsylvania Press.

PRICE-MARS, Jean. 2009 [1929]. Ainsi parla l'Oncle. Chicoutimi: Les Classiques des Sciences Sociales. Disponível em : http://classiques.uqac.ca/classiques/price_mars_jean/ainsi_parla_oncle/ ainsi_parla_oncle.html.

RAMSEY, Kate. 2014. “Possessing the land for Jesus”. In: JOHNSON, P. Christopher (org.). Spirited things: the work of 'possession' in afro-atlantic religions. Chicago: University of Chicago Press. .2011. The spirits and the law: Vodou and power in Haiti. Chicago: University of Chicago Press. RICHMAN, Karen E. 2008. "A more powerful sorcerer: conversion, capital and Haitian transnational migration". New West Indian Guide, 82 (1\&2): 3-45.

2005. Migration and Vodou. Gainesville: University Press of Florida.

RIGAUD, Milo. 1953. La tradition voudoo et le voodoo hä̈tien (son temple, ses mystères, sa magie). Paris: Éditions Niclaus. 


\section{REVISITANDO O VODU: INTERAÇÕES E MOVIMENTOS ENTRE HUMANOS E ESPÍRITOS EM DOIS CONTEXTOS HAITIANOS}

Resumo: Diferentes análises sobre o vodu haitiano apontam para o fato do termo vodou ser empregado para definir rituais que envolvem cantos, danças, tambores, comensalidade e movimentos e promovem a interação entre humanos e espíritos. Contudo, poucos(as) autores(as) exploraram a fundo esta definição, dedicando-se a enfatizar uma imagem estável desse conjunto de práticas e interações. Politicamente, a criação dessa imagem possibilitou ao vodu adquirir o estatuto de religião nacional ganhando legitimidade e eficácia em disputas identitárias e territoriais das quais antropólogos(as) participam ativamente. Neste artigo buscamos aproximar dois contextos etnográficos de pesquisa realizadas em locais relativamente distantes, um situado no Norte e outro no Sul do Haiti, com o principal objetivo de elaborar uma análise das lógicas e das interações com os espíritos em uma perspectiva processual que inclui também o papel de outras agências, de materialidades diversas e de novos contextos situacionais, como as conversões religiosas e o avanço de missionários protestantes pelo país.

Palavras-chave: Haiti, espíritos, vodu, protestantismos, movimento.

\section{REVISITING VODOU: INTERACTIONS AND MOVEMENTS BETWEEN HUMANS AND SPIRITS IN TWO HAITIAN CONTEXTS}

Abstract: Different analysis about Haitian Vodou have pointed out that the term Vodou has been locally used to define rituals in which songs, dances, drums, commensality, and movements promote the interaction between humans and spirits. Nevertheless, few authors have taken this definition further and have instead created a stable image of this ensemble of practices and forms of interaction. Politically, the creation of this image have granted Vodou the status of a national religion acquiring legitimacy and power in identity and territorial claims. This article draws from two different ethnographic contexts in places relatively distant: one setting in the North and another in the South of Haiti. Our main goal is to elaborate an analysis of the logics and interactions with spirits in a perspective that also includes the role of agencies, materialities, and new situations such as religious conversions and the presence of protestant missions in the country.

Keywords: Haiti, spirits, Vodou, protestantisms, movement.

RECEBIDO: $18 / 02 / 2019$

APROVADO: $17 / 07 / 2019$ 